\title{
Soluble PD-1 aggravates progression of collagen-induced arthritis through Th1 and Th17 pathways
}

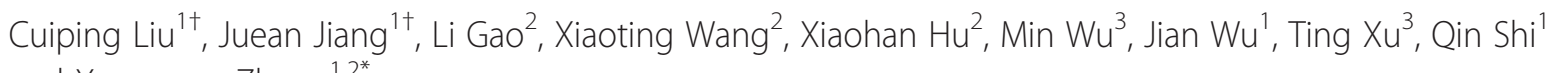
and Xueguang Zhang ${ }^{1,2^{*}}$

\begin{abstract}
Introduction: The programmed cell death 1 (PD-1) protein is a critical regulator of T-cell activation and is also an important therapeutic target for autoimmune diseases. Little is known about the regulation and functional properties of the soluble PD-1 (sPD-1) variant. The aim of this study was to examine the role of sPD-1 in the regulation of human and murine rheumatoid arthritis (RA).

Methods: Expression of cytokines and SPD-1 in sera, synovial fluid, and peripheral blood (PB) mononuclear cells of patients with RA were analyzed by enzyme-linked immunosorbent assay and quantitative polymerase chain reaction. PD-1 function was assessed in PB T cells after stimulation of the cells with anti-CD3 and PD-L1-FC to crosslink PD-1. Recombinant PD-1-Fc was injected intraperitoneally into DBA/1 mice with collagen-induced arthritis (CIA) to analyze the function of sPD-1 in vivo.

Results: High concentrations of sPD-1 were found in sera and synovial fluid of patients with RA. The levels of serum SPD-1 were significantly correlated with titers of rheumatoid factor (RF) $(r=0.306, p=0.005)$ and 28-joint Disease Activity Score $(r=0.545, p<0.001)$. Further characterization of sPD-1 revealed that it functionally blocked the inhibitory effect of membrane-bound PD-1 on T-cell activation. Interferon $\gamma$, tumor necrosis factor $a$, and interleukin 17A were identified as inducers of sPD-1 in vitro. Moreover, PD-1-Fc enhanced proinflammatory cytokine expression, generation of Th1 cells and Th17 cells, and joint pathology in a CIA model.
\end{abstract}

Conclusions: SPD-1 regulates peripheral T-cell responses in both human and murine RA. Thus, SPD-1 may represent an additional biomarker or target in immunomodulatory therapy for RA.

\section{Introduction}

Rheumatoid arthritis (RA) is one of the most common autoimmune diseases, affecting $1 \%$ of the population worldwide [1, 2]. Pathogenic T cells, such as Th1 and Th17 cells, are considered to be critical to the initiation and maintenance of the disease [3-5]. These cells are thought to be triggered locally in an antigen-specific manner, resulting in breakdown of tolerance, synovial inflammation, and autoantibody production [6-9].

\footnotetext{
* Correspondence: xueguangzh@126.com

${ }^{\dagger}$ Equal contributors

'Jiangsu Institute of Clinical Immunology, First Affiliated Hospital of Soochow University, Suzhou 215006, China

${ }^{2}$ Jiangsu Province Key Laboratory of Stem Cell Research, Soochow University, Suzhou 215006, China

Full list of author information is available at the end of the article
}

Programmed cell death 1 (PD-1; also called CD279), which is inducibly expressed on $\mathrm{CD}^{+}{ }^{+} \mathrm{T}$ cells, $\mathrm{CD} 8^{+} \mathrm{T}$ cells, natural killer $\mathrm{T}$ cells, B cells, and activated monocytes, is a type I membrane protein that delivers inhibitory signals to $\mathrm{T}$ cells upon binding of its ligands PD-L1 or PD-L2 [10-13]. PD-1 has been shown to be important for self-tolerance, because spontaneous autoimmune diseases develop in $P D-1^{-/-}$mice [14-16]. In addition, genetic studies revealed that there is an association between polymorphisms in the PDCD1 gene (which encodes PD-1) and susceptibility to autoimmune diseases [17-19], suggesting that PD-1 may play an important role in the development of autoimmune diseases. PD-L1 is widely expressed in activated endothelial and epithelial cells, and it is therefore thought to be important for the fine-tuning of lymphocyte activation at the level of 
synovial tissue $[20,21]$. Increased numbers of PD $-1^{+}$and $\mathrm{PD}-\mathrm{L}^{+}$cells were found in the synovium of patients with active RA [22-24].

There are four alternatively spliced $P D C D-1$ messenger RNA (mRNA) transcripts in addition to the full-length isoform (flPD-1): PD-1 lacking exon 2 (PD-1 $\Delta$ ex2), PD-1 lacking exon 3 (PD-1 $1 \Delta \mathrm{ex} 3), \mathrm{PD}-1$ lacking exons 2 and 3 $(\mathrm{PD}-1 \Delta \mathrm{ex} 2,3)$, and PD-1 lacking exons 2 , 3, and 4 (PD-1 $\Delta$ ex2,3,4). Soluble PD-1 (sPD-1) is encoded by $\mathrm{PD}-1 \Delta \mathrm{ex} 3$, which retains the extracellular domain but lacks the transmembrane domain [25]. Previous studies have shown that sPD-1 promotes T-cell responses by blocking the PD-1/PD ligand pathway [26-31]. Although the function of sPD-1 in antitumor and antiviral immunity has been studied extensively [26-30], its clinical relevance and function in RA is unknown. It was reported that SPD1 occurred at high concentrations in sera and synovial fluid (SF) of patients with RA, and PD-1 levels were found to correlate with titers of rheumatoid factor in (RF) patients with RA [32, 33].

We designed the present study to determine the role of SPD-1 in RA and to test the hypothesis that overexpression of this molecule may contribute to T-cell hyperactivity within the inflamed joint. We examined the clinical significance of SPD-1 in patients with RA by determining sPD-1 levels in serum samples. Recombinant fusion proteins corresponding to the extracellular domains (inclusive of the PD- $1 \Delta \mathrm{ex} 3$ variant) of PD-1 molecule were tested in T-cell proliferation assays using
RA-derived peripheral blood mononuclear cells (PBMCs). The role of sPD-1 in RA was further studied by generating collagen-induced arthritis (CIA) in DBA/1 mice and by using PD-1-Fc to block PD-1 signaling in vivo. Our data suggest that SPD-1 may be a promising biomarker for diagnosing and determining the prognosis of RA. sPD-1 and inflammatory mediators of patients with RA significantly attenuated or reversed T-cell suppression mediated by PD-L1-Fc, verifying that SPD-1 acts as a natural blocker of PD-1/PD-L1 signaling and that soluble factors may interfere with this negative pathway.

\section{Materials and methods}

\section{Patients and specimens}

A total of 83 patients with RA were included in the study (Table 1). All patients fulfilled the American College of Rheumatology criteria for RA. This group included 61 females and 22 males with mean disease duration of $12.1 \pm 8.0$ years. The mean age of the patients was $58.30 \pm 13.01$ years. They were recruited from inpatient and outpatient clinics at the rheumatology departments of the First and Third Affiliated Hospitals of Soochow University. Disease history was recorded for all patients, including presenting symptoms, affected joint counts, and medication history. The activity of disease was evaluated by calculation of 28 -joint Disease Activity Score (DAS28) [34]. The level of RA disease activity can be interpreted as low (Lo-RA; $2.6 \leq \mathrm{DAS} 28 \leq 3.2$ ), moderate (Mo-RA; $3.2<$ DAS2 $\leq 5.1)$, or high (Hi-RA;

Table 1 Clinical information about patients with RA and controls

\begin{tabular}{|c|c|c|c|}
\hline Group & RA & $\mathrm{OA}$ & $\mathrm{HC}$ \\
\hline Sample size, $n$ & 83 & 67 & 88 \\
\hline Age, yr, mean \pm standard deviation & $58.30 \pm 13.01$ & $56.78 \pm 13.98$ & $55.73 \pm 15.19$ \\
\hline \multicolumn{4}{|l|}{ Sex, $n$} \\
\hline Male & 22 & 17 & 20 \\
\hline Female & 61 & 50 & 68 \\
\hline Mean duration of disease, mo (range) & $53.27(1-456)$ & $46.31(1-323)$ & - \\
\hline \multicolumn{4}{|l|}{ Stages of disease, $n$} \\
\hline Early RA ( $\leq 12 \mathrm{mo})$ & 30 & & \\
\hline Late RA (>12 mo) & 53 & & \\
\hline \multicolumn{4}{|l|}{ Activity of disease, $n$} \\
\hline Remission (DAS28 < 2.6) & 10 & - & - \\
\hline $\operatorname{Low}(2.6 \leq \mathrm{DAS} 28 \leq 3.2)$ & 16 & - & - \\
\hline Moderate $(3.2<$ DAS28 $\leq 5.1)$ & 45 & - & - \\
\hline High (DAS28 > 5.1) & 12 & - & - \\
\hline \multicolumn{4}{|l|}{ Manifestations of disease, $n$} \\
\hline Extraarticular & 23 & - & - \\
\hline Limited joint manifestations & 60 & - & - \\
\hline Drug use before study & - & - & - \\
\hline
\end{tabular}

$R A$ rheumatoid arthritis, OA osteoarthritis, $H C$ healthy controls, DAS28 28-joint Disease Activity Score 
DAS28 $>5.1$ ), and a DAS28 $<2.6$ can be considered as remission (Re-RA), according to the European League against Rheumatism criteria. According to extraarticular involvement, the subjects were divided into patients with RA with limited joint manifestations and those with extraarticular manifestations. Eight of the patients received methotrexate (MTX) therapy (10 mg/week for 20 weeks by oral administration, including follow-up periods of 16 and 32 weeks). None of the patients had received steroid or immunosuppressive drugs within 1 year before the study period. Complete sets of paired SF and peripheral blood were obtained from 15 of the 83 patients for paired analyses. Additional sets of SF and paired serum specimens (no cells) derived from the remaining 68 patients with RA were used only for analyses of protein concentrations of sPD-1 by enzymelinked immunosorbent assay (ELISA). Complete sets of paired SF and peripheral blood samples from a total of 67 patients with osteoarthritis (OA) were also included in the study. Control PBMCs and sera were obtained from a group of 88 healthy individuals who were matched for sex ratio and mean age with the patient group from the same hospitals and who had not received immunosuppressive or immunomodulatory drugs for various reasons for at least 2 months before the time of sample collection. Informed consent was obtained from all subjects before sample collection. The study protocol and consent form were approved by the Institutional Medical Ethics Review Board of Soochow University. SF was centrifuged at $350 \times g$ for 3 minutes, and supernatants were collected and immediately stored at $-80{ }^{\circ} \mathrm{C}$ until use. Mononuclear cells were prepared by FicollHypaque separation (GE Healthcare Life Sciences, Little Chalfont, UK) in all cases from blood specimens of patients with RA and controls using the standard protocol.

\section{Preparation of mononuclear cells and isolation of $\mathrm{CD}^{+} \mathrm{T}$ lymphocytes}

PBMCs were isolated from patients with RA or controls. Cells were washed by centrifugation in RPMI 1640 medium and subsequently resuspended in cold phosphate-buffered saline (PBS) containing $2.5 \%$ fetal bovine serum (FBS) at a cell density of $1 \times 10^{7} / \mathrm{ml}$. CD4 $4^{+}$ $\mathrm{T}$ cells were prepared from freshly isolated PBMCs by depleting cells expressing CD8, CD14, CD16, CD19, CD36, CD56, CD123, $\gamma / \delta$-T-cell receptors, and glycophorin A using No-Touch T-cell isolation kits (Miltenyi Biotec, Bergisch Gladbach, Germany). The purity of $\mathrm{CD} 4^{+} \mathrm{T}$ cells was $95-98 \%$ as determined by flow cytometry using specific antibodies.

\section{T-cell stimulation}

Purified T-cell preparations derived from peripheral blood of patients with RA or controls were cultured at
$1 \times 10^{6} / \mathrm{ml}$ in RPMI 1640 medium containing $10 \%$ FBS in the presence of $1 \mu \mathrm{g} / \mathrm{ml}$ anti-CD3 monoclonal antibody (mAb) (clone OKT-3; eBioscience, San Diego, CA, USA) and $0.05 \mu \mathrm{g} / \mathrm{ml}$ anti-CD28 mAb (clone CD28.2; eBioscience). Cells were maintained at $37{ }^{\circ} \mathrm{C}$ in a $5 \%$ $\mathrm{CO}_{2}$ atmosphere for $48 \mathrm{~h}$ and were then harvested for RNA extraction before real-time polymerase chain reaction (PCR) analysis.

\section{Induction of the expression of PD-1 isoforms}

PBMCs from healthy individuals were cultured in 24well plates at $1 \times 10^{6} / \mathrm{ml}$ in RPMI 1640 medium containing $10 \%$ FBS in the presence or absence of a panel of recombinant human cytokines [interferon (IFN)- $\gamma$, interleukin (IL)-17A, or tumor necrosis factor (TNF)- $\alpha$; R\&D Systems, Minneapolis, MN, USA), respectively, at the indicated concentrations. Cells were kept in culture at $37^{\circ} \mathrm{C}$ in a $5 \% \mathrm{CO}_{2}$ atmosphere for $12 \mathrm{~h}$ or $24 \mathrm{~h}$ and were then harvested for isolation of $\mathrm{CD} 4^{+} \mathrm{T}$ cells before real-time PCR analysis.

\section{RNA extraction and real-time PCR}

Total RNA was isolated from cell pellets using an RNeasy Mini Kit (Qiagen, Hilden, Germany). Genomic DNA was removed using RNase-Free DNase (Qiagen). RNA was stored at $-80^{\circ} \mathrm{C}$. First-strand cDNA synthesis was performed using a Sensiscript Reverse Transcription Kit (Qiagen) with random hexamers as the primers. mRNA expression of the genes encoding IFN- $\gamma$, TNF- $\alpha$, IL-2, IL-10, IL-17A, IL-21, flPD-1, and PD-1 $\Delta$ ex3 mRNA was determined by real-time PCR using SYBR Green Master Mix (Applied Biosystems, Foster City, CA, USA). Data were collected and quantitatively analyzed on an ABI PRISM 7900 sequence detection system (Applied Biosystems). The GAPDH gene was used as an endogenous control to normalize for differences in the amount of total RNA in each sample.

\section{Detection of soluble PD-1 and cytokine molecules by ELISA}

Concentrations of sPD-1 were measured quantitatively in SF and sera using ELISA according to our established protocol. For sPD-1, Costar ELISA 96-well plates (Fisher Scientific, Pittsburgh, PA, USA) were precoated with the capture anti-PD-1 mAb (4B9) [31, 34] at $3 \mu \mathrm{g} / \mathrm{ml}$ in $0.05 \mathrm{M}$ carbonate buffer solution ( $\mathrm{pH}$ 9.6) overnight at $4{ }^{\circ} \mathrm{C}$. The coating solution was aspirated off, and unoccupied binding sites on the plates were blocked with $2 \%$ bovine serum albumin in PBS at $37{ }^{\circ} \mathrm{C}$ for $1 \mathrm{~h}$. After being washed three times with PBS containing $0.2 \%$ Tween-20, samples and standards (PD-1 fusion proteins; $R \& D$ Systems) were added to the wells for $2 \mathrm{~h}$ at $37{ }^{\circ} \mathrm{C}$ in duplicate. The specific binding protein was detected with biotinylated anti-PD-1 mAb (bio-9H1, $1 \mu \mathrm{g} / \mathrm{ml}$ ) 
$[31,34]$ for $1 \mathrm{~h}$ at $37{ }^{\circ} \mathrm{C}$, followed by streptavidinhorseradish peroxidase at $1: 2000$ for $1 \mathrm{~h}$ at $37^{\circ} \mathrm{C}$, and then revealed with the substrate 3,3',5,5'-tetramethylbenzidine (Sigma-Aldrich, St. Louis, MO, USA). The reaction was stopped with $2 \mathrm{M} \mathrm{H}_{2} \mathrm{SO}_{4}$, and the plates were analyzed at $450 \mathrm{~nm}$ using a microplate reader (Bio-Rad Laboratories, Hercules, CA, USA). The plates were washed five times with PBS containing $0.2 \%$ Tween-20 after each step. The serial twofold dilutions of the soluble CD28-Fc, PD-L1-Fc, and PD-L2-Fc proteins starting from $100 \mathrm{ng} / \mathrm{ml}$ were detected by the ELISA to assess the specificity of the established system. For the detection of serum expression of TNF- $\alpha$, IFN- $\gamma$, and IL-17A, high-sensitivity ELISA kits for soluble cytokines were obtained from eBioscience and used according to the manufacturer's instructions.

\section{Assessment of PD-1 function}

The effects of PD-1 crosslinking during T-cell activation were determined according to the method described by Bertsias et al. [20]. CD4 $4^{+} \mathrm{T}$ cells $\left(1 \times 10^{5} /\right.$ well $)$ stimulated in 96-well plates with plate-bound anti-CD3 $(1 \mu \mathrm{g} / \mathrm{ml})$ and soluble anti-CD28 $(250 \mathrm{ng} / \mathrm{ml})$ were incubated with a pool of L929-PD-L1 cells (PD-L1 transgenic cell line) or with various concentrations of plate-bound PD-L1-Fc $(0.5 \mu \mathrm{g} / \mathrm{ml}$; R\&D Systems), a chimeric protein containing the extracellular part of human PD-L1 linked to the Fc fragment of human immunoglobulin G1 (IgG1). Then the above $\mathrm{CD}_{4}^{+} \mathrm{T}$ cells were incubated in the presence or absence of the recombinant fusion protein PD-1-Fc for 4 days. After 3 days of coculture supernatants were collected for cytokine measurements, and after 4 days cells were pulsed with the reagent of Cell Counting Kit-8 (CCK-8; Dojindo Molecular Technologies, Kumamoto, Japan) for another $4 \mathrm{~h}$ to measure proliferation.

Induction of $\mathrm{ClA}$ and treatment of DBA/1 mice with PD-1-Fc Male DBA/1 mice were purchased from the Chinese Academy of Sciences (Beijing, China) and maintained in a specific pathogen-free animal facility at Soochow University. All animal procedures were approved by the Institutional Animal Care and Use Committee of Soochow University for the use of laboratory animals. CIA was induced according to the standard protocol. Briefly, an emulsion was formed by dissolving $2 \mathrm{mg} / \mathrm{ml}$ chick type II collagen (CII; Sigma-Aldrich) overnight at $4{ }^{\circ} \mathrm{C}$ in $10 \mathrm{mM}$ acetic acid and combining it with an equal volume of complete Freund's adjuvant containing $5 \mathrm{mg} / \mathrm{ml}$ heat-killed Mycobacterium tuberculosis (Difco H37Ra; BD Diagnostics, Sparks, MD, USA). Eight-week-old mice were injected intradermally at two sites in the base of the tail with a total of $100 \mu \mathrm{l}$ of emulsion. This was repeated as a booster injection 21 days later. In some experiments, DBA/1 mice received intraperitoneal injections of a high dose of PD-1-Fc $(0.15 \mathrm{mg} /$ mouse, $n=7)$ or a low dose of PD-1-Fc $(0.05 \mathrm{mg} / \mathrm{mouse}, n=7)$ on days 1 , 3 , and 5 postimmunization. PD-1-Fc protein consists of the extracellular domains of murine PD-1 linked to the Fc fragment of mouse IgG1. Animals were assessed for redness and swelling of all four limbs, and a clinical score ranging from 0 (no inflammation) to 4 (extensive swelling and erythema of the entire paw) was assigned to each mouse two or three times per week for up to 42 days. After the mice were killed, their rear paws were removed, fixed, decalcified, and embedded in paraffin. Frontal sections of the paw tissue $(5 \mathrm{~mm})$ were stained with hematoxylin and eosin and evaluated according to the presence or absence of inflammatory cell infiltrates (defined as focal accumulations of leukocytes).

\section{CII-specific T-cell proliferation and cytokine production}

Five days or ten weeks after the second immunization, the spleen was removed. Single-cell suspensions of erythrocyte-depleted splenocytes were prepared in RPMI 1640 medium supplemented with $10 \%$ FBS, 2 mM glutamine, $1 \mathrm{mM}$ sodium pyruvate, and antibiotics. Whole splenocytes were seeded into 96-well flat-bottom microtiter plates and cultured in the presence or absence of the indicated amounts of denatured $\left(60^{\circ} \mathrm{C}, 30\right.$ minutes) bovine CII for $72 \mathrm{~h}$. PD-1-Fc protein was added at the start of the assay. CCK- 8 was added $(10 \mu \mathrm{l} /$ well), and incubation was continued for $2 \mathrm{~h}$, followed by measurement of absorbance at $450 \mathrm{~nm}$. Supernatants from similar cultures were collected after $96 \mathrm{~h}$ for assessment of cytokine production using a cytometric bead array (CBA; BD Biosciences, San Jose, CA, USA).

\section{Cytometric bead array}

Cytokine concentrations in supernatants were determined using a mouse Th1/Th2/Th17 CBA kit (BD Biosciences), which allowed for the simultaneous detection of IL-2, IL-4, IL-6, IL-10, TNF- $\alpha$, IFN- $\gamma$, and IL-17A. Aliquoted samples were thawed, and CBA analysis was performed according to the manufacturer's protocol. Briefly, beads coated with capture antibodies were mixed, and $50 \mu \mathrm{l}$ of the capture bead mixture was added to $50 \mu \mathrm{l}$ of sample. To these sample bead complexes, $50 \mu \mathrm{l}$ of phycoerythrin (PE)-conjugated detection antibody was added, and this mixture was incubated for $3 \mathrm{~h}$ in the dark at room temperature. Samples were washed with $1 \mathrm{ml}$ of wash buffer at $1100 \mathrm{rpm}$ for 5 minutes, and the pellets were resuspended in $300 \mathrm{ml}$ of wash buffer. Cytokine standards were serially diluted to facilitate the construction of calibration curves necessary for determining protein concentrations of test samples. Flow cytometric analysis was performed on a BD FACSCanto II (BD Immunocytometry Systems, Erembodegem, Belgium) with BD FACSDIVA version 6 software, and data were 
analyzed with FCS Express version 3 software (De Novo Software, Glendale, CA, USA).

\section{Antibodies and flow cytometry}

Human cells were stained with the following antibodies: fluorescein isothiocyanate (FITC)-anti-CD4, PE-cyanine 7 (Cy7)-conjugated anti-IFN- $\gamma$, anti-IL-4, anti-IL-17A, and anti-TNF- $\alpha$ (all from BioLegend, San Diego, CA, USA). Mouse cells were stained with FITC-conjugated anti-CD4, PE-anti-chemokine (C-X-C) motif receptor 5, PE-Cy7-conjugated anti-inducible costimulatory molecule, anti-IFN- $\gamma$, anti-IL-4, anti-IL-17A, and anti-TNF- $\alpha$ (all from BioLegend).

Intracellular staining was performed as follows. PBMCs or splenocytes were stimulated with $50 \mathrm{ng} / \mathrm{ml}$ phorbol 12-myristate 13-acetate, $750 \mathrm{ng} / \mathrm{ml}$ ionomycin (both from Sigma-Aldrich), and $1 \mu \mathrm{l} / \mathrm{ml}$ GolgiStop (BD Biosciences) for $5 \mathrm{~h}$ at $37^{\circ} \mathrm{C}$. Surface staining was performed for 20 minutes with FITC anti-human/antimouse CD4 antibody on ice. Cells were washed and resuspended in fixation/permeabilization solution (BD Cytofix/Cytoperm kit; BD Biosciences) and stained with PE-Cy7-conjugated anti-IFN- $\gamma$, anti-IL-4, anti-IL$17 \mathrm{~A}$, and anti-TNF- $\alpha$ (all from BioLegend) for flow cytometric analysis. PE-Cy7-conjugated IgG1 and FITC-conjugated IgG1 (BD Biosciences) were used as isotype controls. All data were analyzed using FlowJo software (FlowJo, Ashland, OR, USA).

\section{Computed tomographic scanning}

Micro-computed tomography was performed using a cone beam scanner ( $\mu$ CT 20; SCANCO Medical, Brüttisellen, Switzerland) with a fixed $x$-ray fan beam of $7-\mu \mathrm{m}$ spot size at $50 \mathrm{kVp}$ and $160 \mathrm{~mA}$. Integration time was 140 milliseconds, and slices were scanned at high resolution (1024x 1024-pixel matrix per slice) and size of 25 microvoxels.

\section{Histological and radiological assessments of arthritis}

CIA mice were killed at day 35 or day 60 . Anteroposterior radiographs of the four limbs were obtained with a cabinet soft $\mathrm{x}$-ray apparatus (CMB-2; Softex, Tokyo, Japan). The hind paws were then removed, fixed in formalin, decalcified in $10 \%$ ethylenediaminetetraacetic acid, embedded in paraffin, sectioned, and stained with hematoxylin and eosin.

\section{Statistical analysis}

All statistical analyses were performed using IBM SPSS 20.0 for Windows software (IBM, Armonk, NY, USA). All the quantitative data are presented as mean \pm standard deviation. Student's $t$ test was used to analyze differences between the groups. A Mann-Whitney $U$ test based on nonparametric analysis was performed for independent samples. A paired-samples $t$ test or nonparametric Wilcoxon signed-rank test was performed for paired samples. For multiple comparisons, one-way analysis of variance or the Kruskal-Wallis test was initially performed to determine whether an overall statistically significant change existed before using the paired or unpaired Student's $t$ test. For correlation analyses, a Spearman's $r$ value derived from Pearson's $r$ was calculated. A $p$ value less than 0.05 was considered statistically significant.

\section{Results}

SPD-1 levels correlate with clinical parameters and cytokine concentration in sera and SF of patients with RA Higher concentrations of SPD- 1 were detected in the SF and serum of patients with RA than in OA-SF $(p<0.0001)$ and control serum specimens $(p=0.038)$ (Fig. 1a). The levels of sPD-1 in serum specimens from Mo-RA $(p=0.017)$ and Hi-RA $(p=0.048)$ patients were higher than those in Re-RA patients and Lo-RA patients (Fig. 1b). Clinical analyses showed that sPD-1 levels were correlated with DAS28 $(r=0.545, p<0.001)$ and RF content $(r=0.306, p=0.005) \quad$ (Fig. 1d, e). MTX treatment significantly reduced sPD-1 level compared with pretherapy levels $(p=0.011)$ (Fig. 1f). In addition, sPD-1 levels in RA serum samples correlated significantly with the concentrations of TNF- $\alpha$, IFN- $\gamma$, and IL-17A in the same serum samples (Fig. $1 \mathrm{~g}-\mathrm{i}$ ). These results suggest that $\mathrm{SPD}-1$ is aberrantly expressed in RA serum, and the level of sPD-1 correlates with the serum concentrations of TNF- $\alpha$, IFN- $\gamma$, and IL-17A. Taken together, these results suggest that high levels of circulating SPD-1 are observed in RA and may be associated with disease severity and activity.

\section{Induction of PD-1 $1 \mathrm{ex} 3$ splicing variants by proinflammatory cytokines}

Next, we examined the expression of PD-1 $\Delta$ ex3. The $\mathrm{PD}-1 \Delta$ ex 3 splice variant lacks the membrane-spanning domain but has an unchanged extracellular domain, suggesting that the putative translational product is SPD-1 [25]. We found that patients with RA had increased expression of PD-1 $1 \Delta \mathrm{ex} 3$ compared with patients with $\mathrm{OA}$ and healthy controls $(p<0.028)$ (Fig. 2a). It has been shown that proinflammatory cytokines might be responsible for the progression of arthritis [6]. We found that the mRNA levels of the genes encoding the proinflammatory cytokines IFN- $\gamma$, TNF- $\alpha$, IL-4, IL-21, and IL-17A were higher in the PBMCs of patients with RA (Fig. 2b), and the IFN- $\gamma$, TNF- $\alpha$, IL-10, and IL-17A mRNA levels were positively correlated with the mRNA level of PD$1 \Delta$ ex3 (Fig. 2c-h). We hypothesized that these proinflammatory cytokines, which are expressed abundantly in RA serum, might be responsible for the induction of increased expression of $\mathrm{PD}-1 \Delta \mathrm{ex} 3$ in $\mathrm{T}$ cells in RA. 


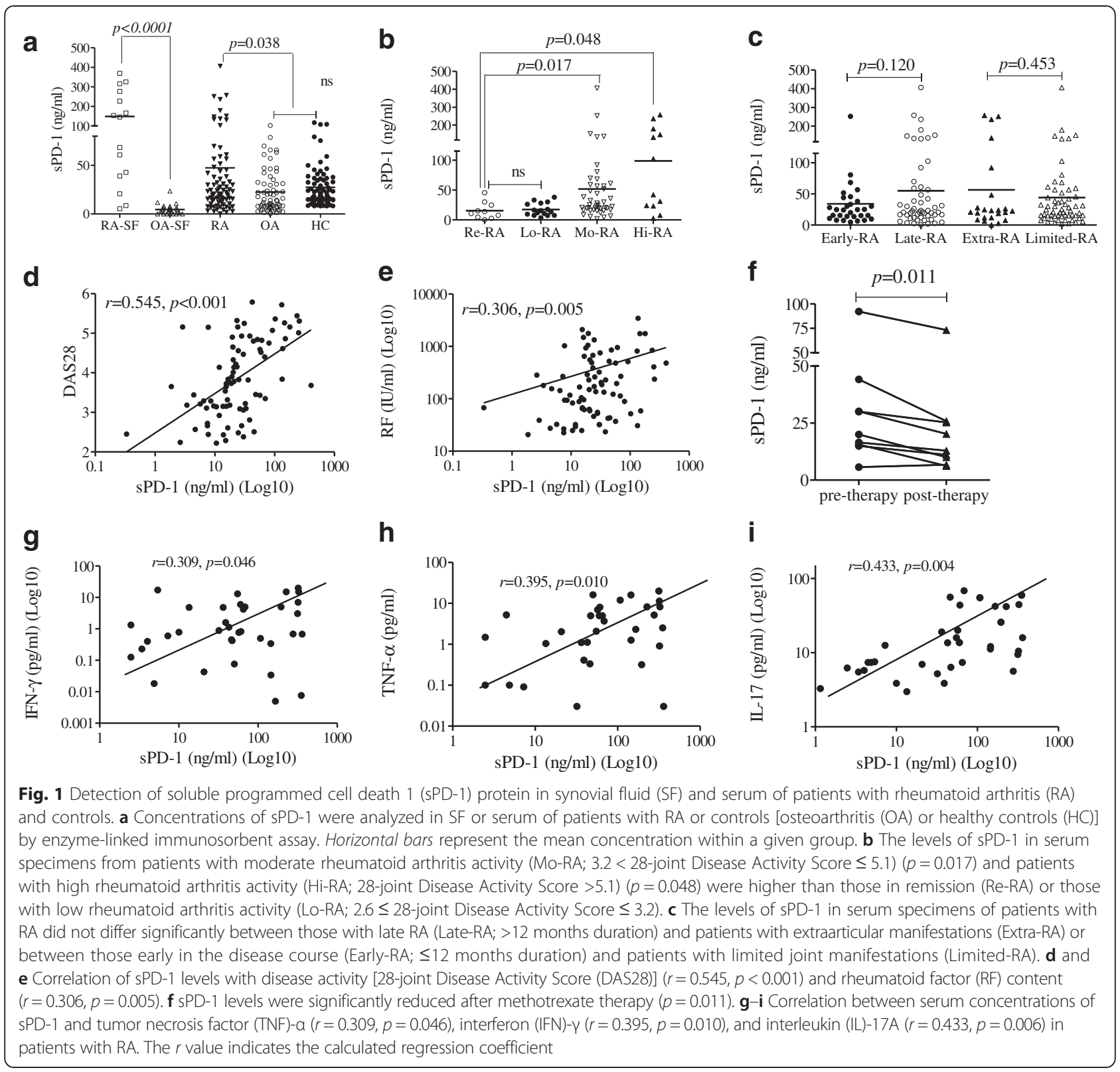

Thus, we analyzed the ability of the proinflammatory cytokines IFN- $\gamma$, TNF- $\alpha$, and IL-17A to induce expression of PD- $1 \Delta$ ex 3 in vitro in PBMCs obtained from healthy individuals. As shown in (Fig. 2i-k), the expression of $\mathrm{PD}-1 \Delta \mathrm{ex} 3$ in $\mathrm{T}$ cells could be selectively induced by IFN- $\gamma$, TNF- $\alpha$, and IL-17A in a dose-dependent manner, whereas the expression of flPD-1 was not significantly affected by the addition of the indicated cytokines.

\section{sPD-1 block PD-1 pathway in vitro}

$\mathrm{CD}^{+}{ }^{+} \mathrm{T}$ cells were incubated with a pool of L929-PD-L1 cells or with PD-L1-Fc protein in the presence or absence of the recombinant fusion protein PD-1-Fc (PD-1-Fc) for 4 days, then cocultured with CCK- 8 for the proliferation assay. PD-1-Fc promoted proliferation of $\mathrm{CD}^{+} \mathrm{T}$ cells cocultured with PD-L1 transgenic cells $(p=0.0074)$ (Fig. 3a). Meanwhile, T-cell suppression by PD-L1-Fc was neutralized by PD-1-Fc $(p<0.05)$ (Fig. 3b). PBMCs from patients with RA and healthy controls were incubated with anti-CD3 in the presence or absence of PD-1-Fc for 4 days with the addition of brefeldin $\mathrm{A}$ for the last $16 \mathrm{~h}$. The cells were then collected and stained for the cell surface marker CD4, as well as for the intracellular cytokines IFN- $\gamma$, TNF- $\alpha$, IL-4, and IL-17 after fixation/permeabilization. We found that PD-1-Fc increased the percentage of $\mathrm{CD} 4^{+} \mathrm{IFN}-\gamma^{+}$and $\mathrm{CD} 4^{+} \mathrm{IL}-17^{+}$cells (Fig. $3 \mathrm{c}$ ), suggesting that $\mathrm{sPD}-1$ has the ability to promote Th1/Th17 cells, which are critical pathogenic T cells in autoimmune diseases, including RA. 


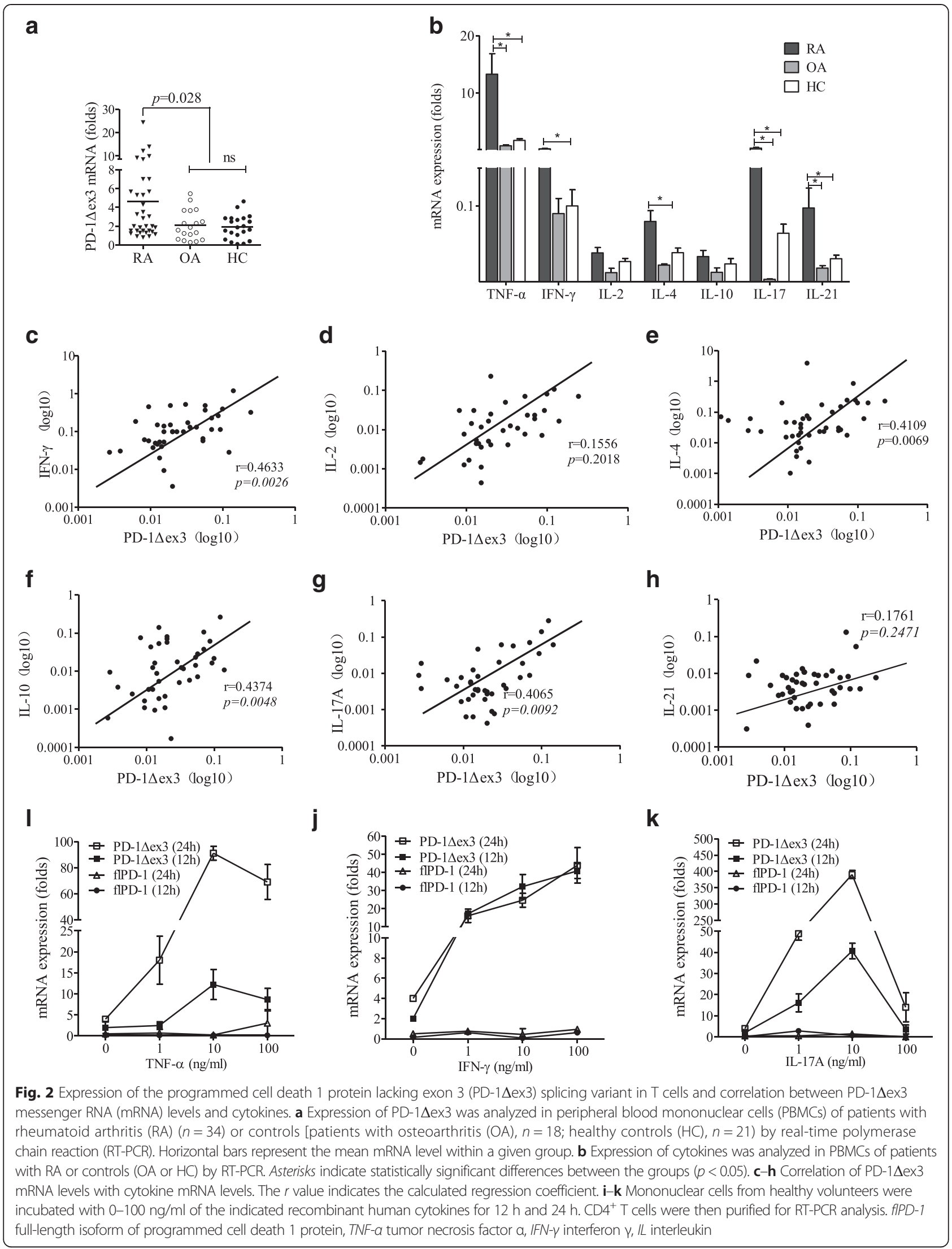




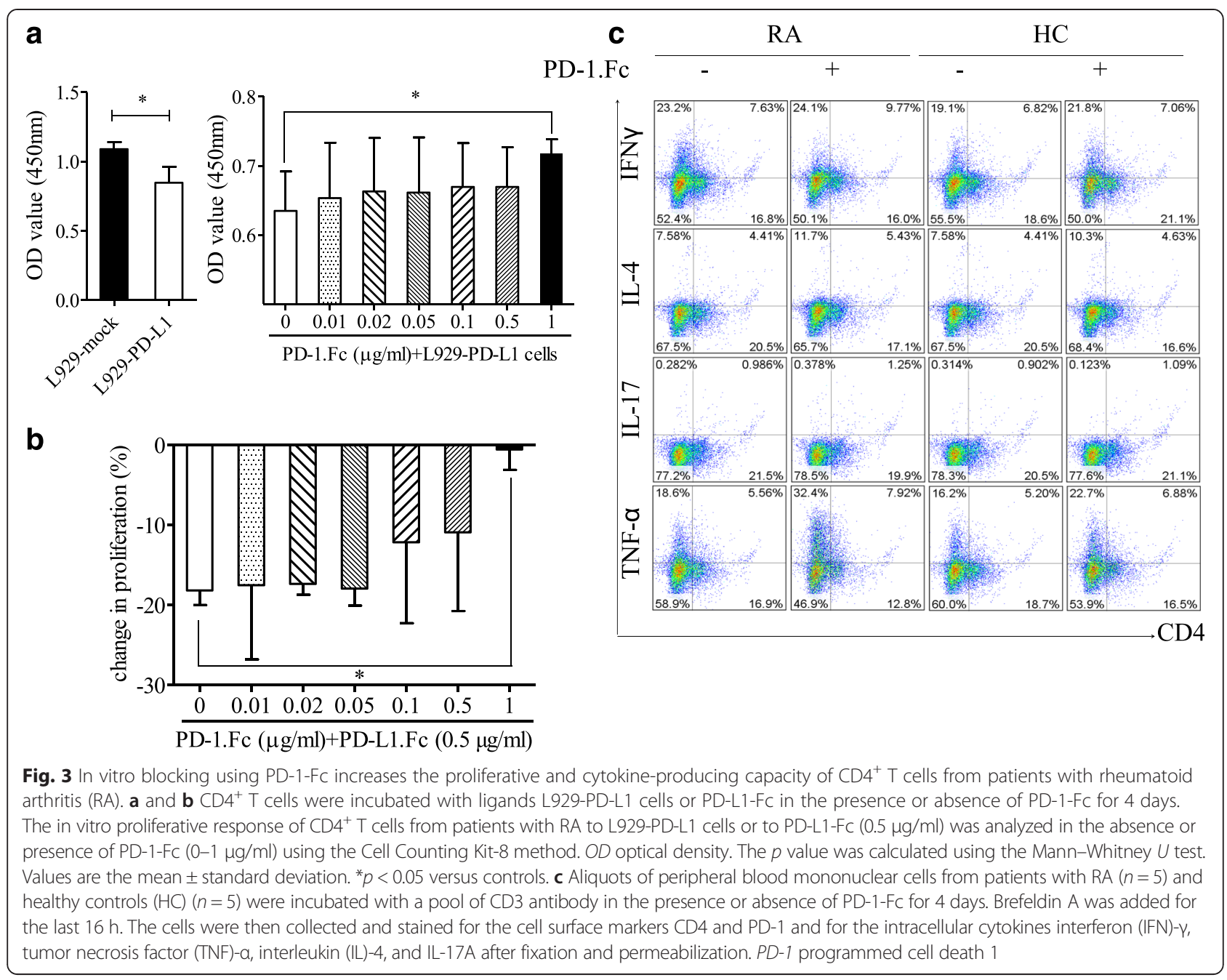

Systemic administration of sPD-1 to Cll-immunized mice accelerates arthritis onset and joint damage, and increases autoantibody production and Th1/Th17 responses

To directly assess the role of sPD-1 in inflammatory arthritis in vivo, CIA was induced in DBA/1 mice, followed by intraperitoneal injection with either soluble murine PD-1-Fc fusion protein or PBS as a control. PD-1-Fc-treated mice developed more severe arthritis. Administration of only three doses of PD-1Fc, starting at day 1 after the second immunization, markedly exacerbated arthritis progression associated with severe synovial hyperplasia, cartilage damage, and bone erosion (Fig. 4a, g). On computed tomographic scans, we detected obvious narrowing of the joint space and bone erosion compared with IgG-treated controls (Fig. 4e, f). To evaluate whether PD-1-Fc could affect established arthritis, we treated mice with established inflamed limbs at a clinical score of $8.0 \pm$ 2.0 with PD-1-Fc. PD-1-Fc rapidly enhanced arthritic progression with significantly increased joint damage (Fig. 4b, c).
Immunization with CII elicits a specific humoral response in all mice. Although levels of anti-CII antibody are not strictly correlated to arthritis scores, they are usually high in sera from severely diseased mice. Serum levels of anti-CII autoantibody in DBA/1 and CIA mice treated with PBS or PD-1-Fc were analyzed using ELISA at day 50 after the second immunization. The PD-1-Fc-treated mice had significantly increased serum levels of anti-CII autoantibody compared with the controls $(p<0.05)$ (Fig. 5a). Analysis of spleen cells from PD-1-Fc-treated mice revealed significantly upregulated mRNA levels of TNF- $\alpha$, IFN- $\gamma$, and IL-17 F. Expression of RAR-related orphan receptor $\alpha$ and T-bet mRNA was also markedly increased (Fig. 5b). In the PD-1-Fc-treated group, we found significantly increased numbers of Th1 and Th17 cells in the spleen (Fig. 5c, d).

To better understand how PD-1-Fc influences the T-cell response, we studied the effect of $\mathrm{PD}-1-\mathrm{Fc}$ on the proliferation and cytokine secretion of splenocytes in vitro. We cultured splenocytes from CIA mice with or without PD-1-Fc and found that PD-1-Fc treatment enhanced the ability of 


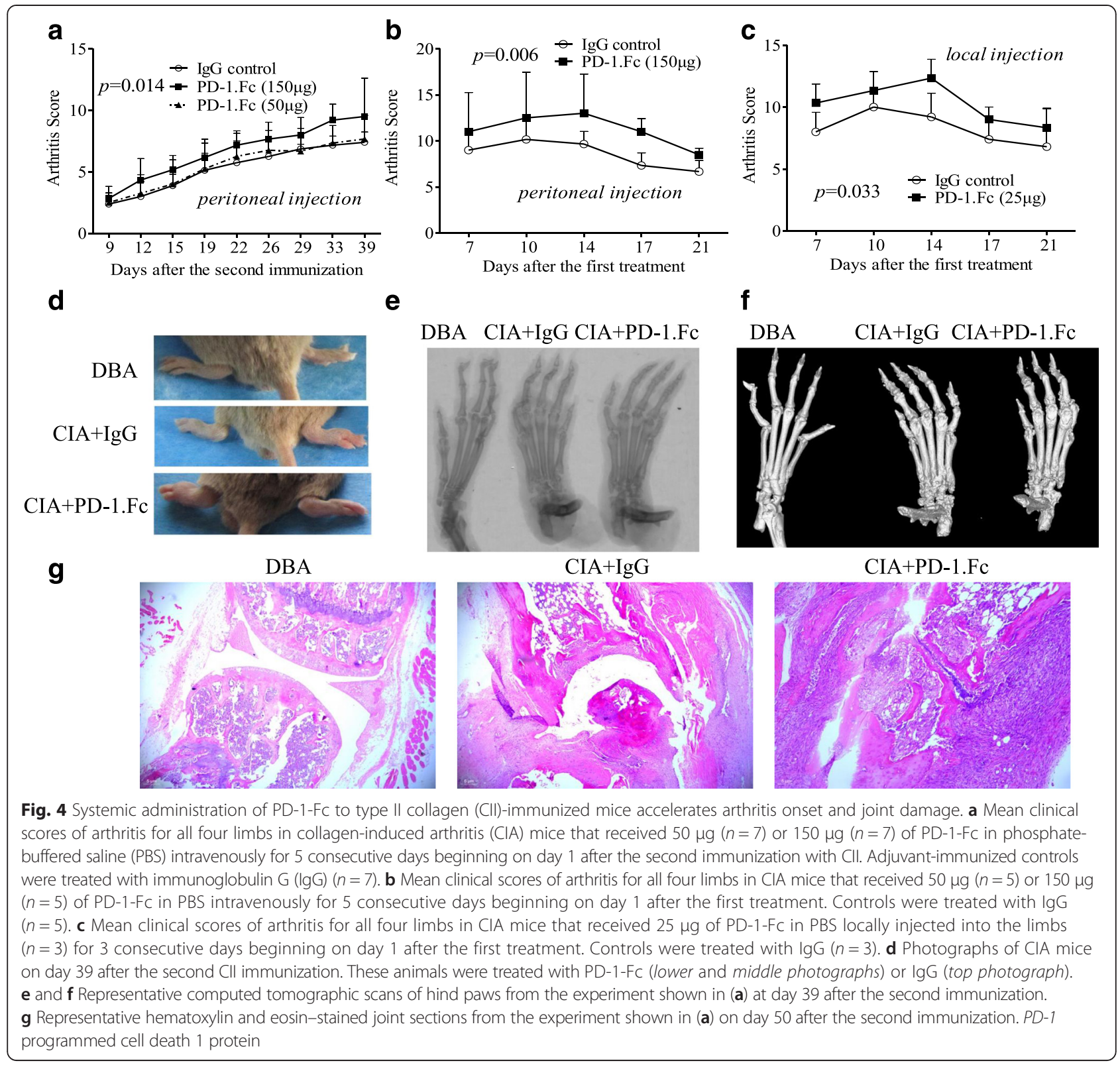

splenocytes to proliferate (Fig. 6a). After 4 days of culture IL-2, IL-4, IL-6, TNF- $\alpha$, IL-17A, and IFN- $\gamma$, levels were quantified in the supernatants. As shown in Fig. $6 \mathrm{~b}$, one of the main effects of PD-1-Fc was to increase the production of IL-2, IL-6, TNF- $\alpha$, IL-17A, and IFN- $\gamma$ proteins. IL-4 production was not modified in the presence of PD-1-Fc (Fig. 6b, c). These results were further confirmed by intracellular cytokine staining (Fig. 6d). These results suggest that PD-1-Fc promotes CIA by enhancing Th1 and Th17 responses.

\section{Discussion}

PD-1 and its ligands PD-L1 and PD-L2 are critical for tolerance and immune homeostasis by inhibiting T-cell activation $[10,12]$. PD-1 ${ }^{-/-}$mice develop many kinds of autoimmune diseases [14-16].

Recent reports showed that sPD-1 can block the PD1/PD-L1 pathway in regulating T-cell function during chronic infection, antitumor immunity, and autoimmune diseases [26-29]. He et al. found that sPD-1 can bind PD-1 ligands, block PD-1/ligand interactions, and enhance the cytotoxicity of tumor-specific CTLs [28]. sPD-1 rescues the proliferative response of simian immunodeficiency virus-specific $\mathrm{CD}^{+}$and $\mathrm{CD} 8^{+} \mathrm{T}$ cells during chronic infection [29]. Previously, we demonstrated the overexpression of PD- 1 on $\mathrm{CD}_{4}^{+}$and $\mathrm{CD} 8^{+}$ $\mathrm{T}$ cells and elevated serum levels of sPD-1 in patients with aplastic anemia [31]. We propose that upregulation 


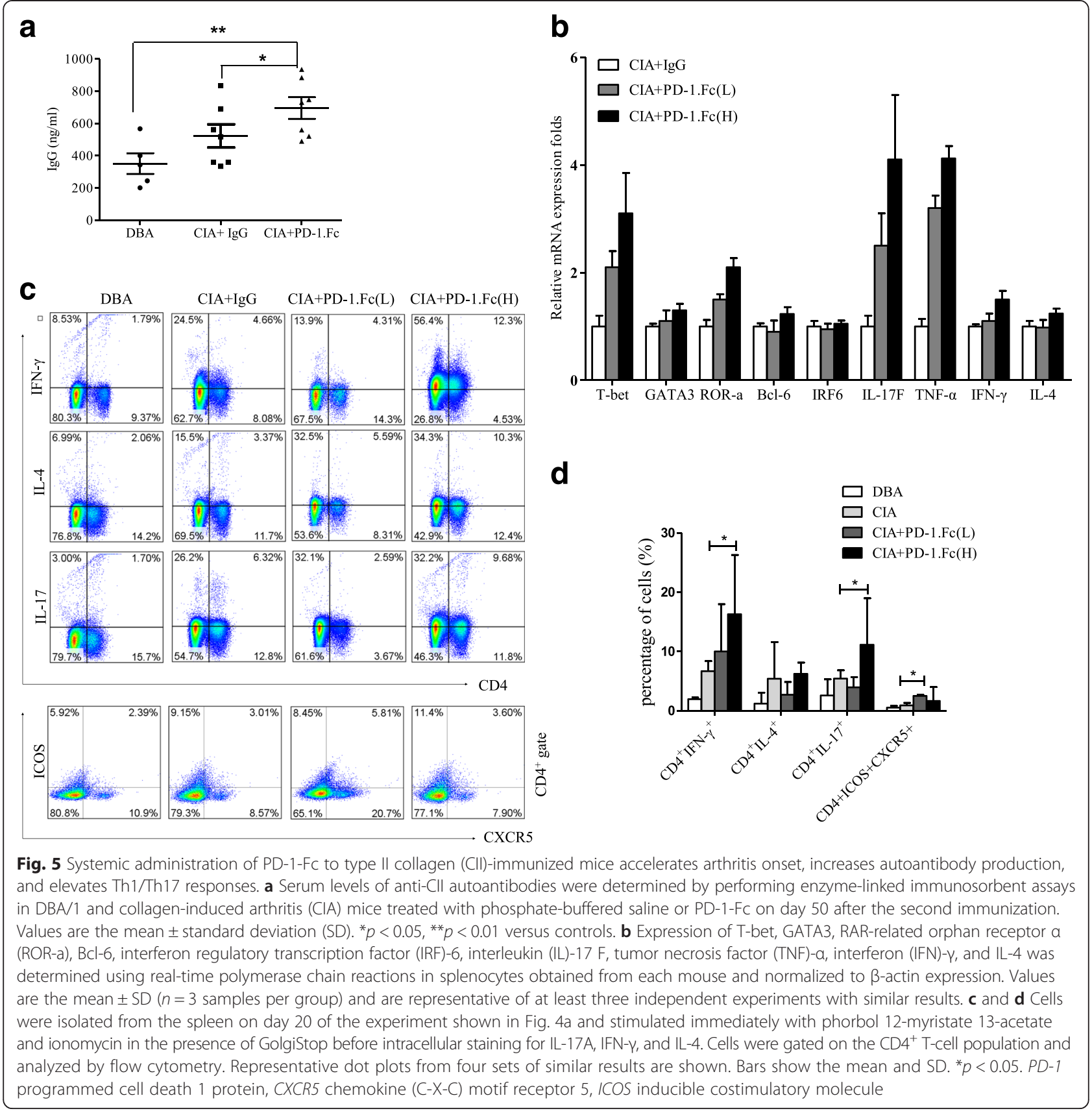

of sPD-1 molecules might block the PD-1/PD-L1 signaling pathway. Few data are available concerning serum sPD-1 in RA. Recent studies demonstrated that synovial and serum SPD-1 levels are elevated in patients with RA and are correlated with titers of RF [32, 33]. However, the expression and clinical significance of sPD-1 in RA are not well known.

We therefore first explored the clinical significance of sPD-1 in patients with RA by determining the levels of sPD-1 in serum samples. Both sPD-1 levels in serum samples and PD-1 $1 \mathrm{ex} 3$ mRNA expression in PBMCs from patients with RA were elevated compared with those from patients with OA and healthy controls. Clinical analyses showed that SPD-1 levels were closely correlated with disease activity and RF content in patients with RA. The significant correlation between SPD-1 and the DAS28 suggests that SPD-1 may be a marker of disease activity. This result confirms a previous study showing that circulating SPD-1 is derived, at least in part, from inflamed synovium [31] and that serum sPD-1 may reflect RA disease activity because it is associated with synovial inflammation observed on clinical examination [32]. Our findings suggest that aberrant overexpression of sPD-1 might block the PD-1/PD-L1 inhibitory 


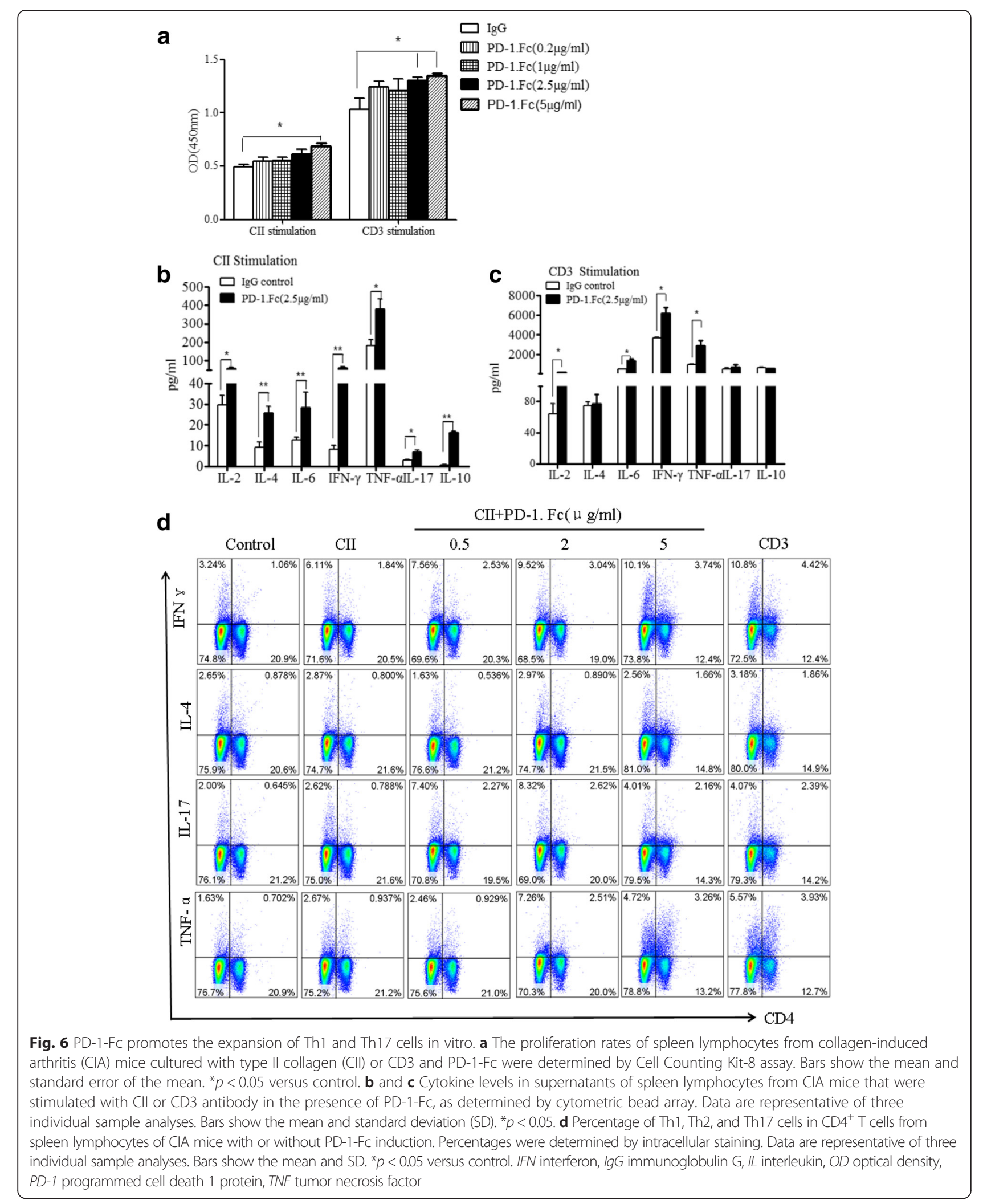


pathway and may be associated with persistent activation of self-reactive $\mathrm{T}$ cells in RA, leading to long-term disease progression. We also showed that the PD- $1 \Delta \mathrm{ex} 3$ splice variant encoding for SPD-1 is specifically associated with RA but is not related to the T-cell activation state, because expression of this variant is markedly increased in $\mathrm{T}$ cells derived from RA [31].

A significant portion of this study was devoted to investigating the molecular mechanism of higher expression of SPD- 1 in activated $\mathrm{CD} 4^{+} \mathrm{T}$ cells. It was previously shown that proinflammatory cytokines might be responsible for the progression of arthritis. We found that the proinflammatory cytokines produced abundantly in RA serum might be responsible for inducing the increased expression of PD-1 1 ex 3 in $\mathrm{CD}^{+} \mathrm{T}$ cells. Upregulated expression of PD-1 in RA does not appear to suppress the function of T cells. We therefore hypothesized that the expected function of PD-1 overexpression in $\mathrm{T}$ cells was neutralized. To test this hypothesis, we examined the effect of a recombinant fusion protein containing the extracellular domain of PD-1 (as encoded by the PD-1 $1 \Delta$ ex 3 variant) on T-cell proliferation and in the CIA mouse model. Addition of PD-1 fusion protein enhanced T-cell proliferation in vitro $(p<0.05)$. This finding indicated that the regulatory properties of membrane-bound PD-1 and PD-L1 were altered by the presence of their soluble forms in the experimental system.

PD-1 blockade was found to shift antigen-induced cellular reactivity toward a proinflammatory Th1/Th17 response, as evidenced by enhanced production of IFN- $\gamma$, IL-2, TNF- $\alpha$, IL-6, and IL-17A, and to reduce production of the Th2 cytokines IL-5 and IL-13 [35]. We showed that PD-1-Fc enhanced the severity of autoimmune arthritis in mice with CIA. Additionally, levels of pathogenic IgG autoantibody to mouse type II collagen were increased in PD-1-Fc-treated CIA mice, and levels of Th1 and Th17 cells were increased in the spleen, suggesting that the $\mathrm{T}$ cells may have systemic effects on the B-cell response as well as local effects on the inflammatory environment. This work demonstrates that $\mathrm{CD} 4^{+} \mathrm{T}$ cells specific for sPD-1 can amplify disease severity after onset of CIA.

\section{Conclusions}

We provide evidence that $\mathrm{SPD}-1$ plays a key inhibitory role in the PD-1/PD-L1 pathway in regulating T-cell function in RA. sPD-1 occurred at high concentrations in the serum and SF of patients with RA. It blocked the regulatory effect of membrane-bound PD-1 on T-cell activation. We identified IFN- $\gamma$, TNF- $\alpha$, and IL-17A as inducers of sPD-1. sPD-1 aggravated progression of CIA through induction of Th1/Th17 responses. sPD-1 regulated peripheral $\mathrm{T}$-cell responses in both human and murine RA. Thus, sPD-1 may represent an additional target for immunomodulatory therapy in RA.

\section{Abbreviations}

CBA: cytometric bead array; CIA: collagen-induced arthritis; Cll: type II collagen; CXCR5: chemokine (C-X-C) motif receptor 5; Cy7: cyanine 7; DAS28: 28-joint Disease Activity Score; ELISA: enzyme-linked immunosorbent assay; FBS: fetal bovine serum; FITC: fluorescein isothiocyanate; HC: healthy control; Hi-RA: high rheumatoid arthritis activity (28-joint Disease Activity Score $>5.1$ ); ICOS: inducible costimulatory molecule; IFN: interferon; Ig: immunoglobulin; IL: interleukin; IRF: interferon regulatory transcription factor; Lo-RA: low rheumatoid arthritis activity (2.6 $\leq 28$-joint Disease Activity Score 53.2$)$; mAb: monoclonal antibody; Mo-RA: moderate rheumatoid arthritis activity $(3.2<28$-joint Disease Activity Score $\leq 5.1)$; mRNA: messenger RNA; MTX: methotrexate; OA: osteoarthritis; OD: optical density; PBMC: peripheral blood mononuclear cell; PBS: phosphate-buffered saline; PCR: polymerase chain reaction; PD-1: programmed cell death 1; PE: phycoerythrin; qRT-PCR: quantitative real-time reverse transcription polymerase chain reaction; RA: rheumatoid arthritis; Re-RA: rheumatoid arthritis in remission (28-joint Disease Activity Score <2.6); RF: rheumatoid factor; RORa: RAR-related orphan receptor a, SD, standard deviation; SF: synovial fluid; TNF: tumor necrosis factor.

\section{Competing interests}

The authors declare that they have no competing interests.

\section{Authors' contributions}

XZ had full access to all of the data in the study and take responsibility for the integrity of the data and the accuracy of the data analysis. CL and JJ carried out the fluorescence-activated cell sorting and molecular analyses, performed the statistical analysis, and drafted the manuscript. LG performed biomarker analysis and critically revised the manuscript. XH and XW performed the molecular studies and helped to draft the manuscript. MW and JW were involved in the conception of the study and contributed to study design, and data interpretation, drafting of the manuscript. TX and QS participated in study design and coordination and helped to draft the manuscript. All authors read and approved the final manuscript.

\section{Acknowledgments}

This work was supported by grant 2013CB530501 from the National Program on Key Basic Research Project (973 Program); grants 31320103918, 30930085, and 31170834 from the National Natural Science Foundation of China; and grant SYS201331 from the Science and Technology Project of Suzhou.

\section{Author details}

${ }^{1}$ Jiangsu Institute of Clinical Immunology, First Affiliated Hospital of Soochow University, Suzhou 215006, China. ${ }^{2}$ Jiangsu Province Key Laboratory of Stem Cell Research, Soochow University, Suzhou 215006, China. ${ }^{3}$ Department of Rheumatology, Third Affiliated Hospital of Soochow University, Changzhou 213003, China.

Received: 21 August 2015 Accepted: 9 November 2015

Published online: 25 November 2015

\section{References}

1. Klareskog L, Catrina Al, Paget S. Rheumatoid arthritis. Lancet. 2009;373:659-72.

2. Scott DL, Wolfe F, Huizinga TW. Rheumatoid arthritis. Lancet. 2010;376:1094-108.

3. Leipe J, Grunke M, Dechant C, Reindl C, Kerzendorf U, Schulze-Koops H, et al. Role of Th17 cells in human autoimmune arthritis. Arthritis Rheum. 2010;62:2876-85.

4. Goronzy JJ, Weyand CM. T-cell regulation in rheumatoid arthritis. Curr Opin Rheumatol. 2004;16:212-7.

5. Lundy SK, Sarkar S, Tesmer LA, Fox DA. Cells of the synovium in rheumatoid arthritis: T lymphocytes. Arthritis Res Ther. 2007;9:202.

6. Burmester GR, Feist E, Dörner T. Emerging cell and cytokine targets in rheumatoid arthritis. Nat Rev Rheumatol. 2014;10:77-88.

7. Komatsu N, Takayanagi H. Autoimmune arthritis: the interface between the immune system and joints. Adv Immunol. 2012;115:45-71.

8. Mclnnes IB, Schett G. Cytokines in the pathogenesis of rheumatoid arthritis. Nat Rev Immunol. 2007;7:429-42. 
9. McInnes IB, Schett G. The pathogenesis of rheumatoid arthritis. N Engl J Med. 2011;365:2205-19.

10. Francisco LM, Sage PT, Sharpe AH. The PD-1 pathway in tolerance and autoimmunity. Immunol Rev. 2010;236:219-42.

11. Fife BT, Pauken KE. The role of the PD-1 pathway in autoimmunity and peripheral tolerance. Ann N Y Acad Sci. 2011;1217:45-59.

12. Keir ME, Butte MJ, Freeman GJ, Sharpe AH. PD-1 and its ligands in tolerance and immunity. Annu Rev Immunol. 2008;26:677-704.

13. Riella LV, Paterson AM, Sharpe AH, Chandraker A. Role of the PD-1 pathway in the immune response. Am J Transplant. 2012;12:2575-87.

14. Nishimura H, Nose M, Hiai H, Minato N, Honjo T. Development of lupus-like autoimmune diseases by disruption of the PD-1 gene encoding an ITIM motif-carrying immunoreceptor. Immunity. 1999;11:141-51.

15. Nishimura H, Okazaki T, Tanaka Y, Nakatani K, Hara M, Matsumori A, et al. Autoimmune dilated cardiomyopathy in PD-1 receptor-deficient mice. Science. 2001:291:319-22.

16. Wang J, Yoshida T, Nakaki F, Hiai H, Okazaki T, Honjo T. Establishment of NOD-Pdcd ${ }^{-1-}$ mice as an efficient animal model of type I diabetes. Proc Natl Acad Sci U S A. 2005;102:11823-8.

17. Suarez-Gestal M, Ferreiros-Vidal I, Ortiz JA, Gomez-Reino JJ, Gonzalez A. Analysis of the functional relevance of a putative regulatory SNP of PDCD1, PD-1.3, associated with systemic lupus erythematosus. Genes Immun. 2008:9:309-15

18. Newby PR, Roberts-Davies EL, Brand OJ, Heward JM, Franklyn JA, Gough SC, et al. Tag SNP screening of the PDCD1 gene for association with Graves' disease. Clin Endocrinol. 2007;67:125-8.

19. Kong EK, Prokunina-Olsson L, Wong WH, Lau CS, Chan TM, Alarcon-Riquelme $M$, et al. A new haplotype of PDCD1 is associated with rheumatoid arthritis in Hong Kong Chinese. Arthritis Rheum. 2005;52:1058-62.

20. Bertsias GK, Nakou M, Choulaki C, Raptopoulou A, Papadimitraki E, Goulielmos G, et al. Genetic, immunologic, and immunohistochemical analysis of the programmed death 1/programmed death ligand 1 pathway in human systemic lupus erythematosus. Arthritis Rheum. 2009;60:207-18.

21. Gianchecchi E, Delfino DV, Fierabracci A. Recent insights into the role of the PD-1/PD-L1 pathway in immunological tolerance and autoimmunity. Autoimmun Rev. 2013;12:1091-100.

22. Hatachi S, Iwai Y, Kawano S, Morinobu S, Kobayashi M, Koshiba M, et al. CD4 + PD-1+ T cells accumulate as unique anergic cells in rheumatoid arthritis synovial fluid. J Rheumatol. 2003;30:1410-9.

23. Raptopoulou AP, Bertsias G, Makrygiannakis D, Verginis P, Kritikos I, Tzardi M, et al. The programmed death $1 /$ programmed death ligand 1 inhibitory pathway is up-regulated in rheumatoid synovium and regulates peripheral T cell responses in human and murine arthritis. Arthritis Rheum. 2010;62:1870-80.

24. Moret FM, van der Wurff-Jacobs KM, Bijlsma JW, Lafeber FP, van Roon JA. Synovial T cell hyporesponsiveness to myeloid dendritic cells is reversed by preventing PD-1/PD-L1 interactions. Arthritis Res Ther. 2014;16:497.

25. Nielsen C, Ohm-Laursen L, Barington T, Husby S, Lillevang ST. Alternative splice variants of the human PD-1 gene. Cell Immunol. 2005;235:109-16.

26. Shin SP, Seo HH, Shin JH, Park HB, Lim DP, Eom HS, et al. Adenovirus expressing both thymidine kinase and soluble PD1 enhances antitumor immunity by strengthening CD8 T-cell response. Mol Ther. 2013;21:688-95.

27. Amancha PK, Hong JJ, Rogers $K$, Ansari AA, Villinger F. In vivo blockade of the programmed cell death-1 pathway using soluble recombinant PD-1-Fc enhances $\mathrm{CD}^{+}$and $\mathrm{CD}^{+} \mathrm{T}$ cell responses but has limited clinical benefit. J Immunol. 2013;191:6060-70

28. He YF, Zhang GM, Wang XH, Zhang H, Yuan Y, Li D, et al. Blocking programmed death-1 ligand-PD-1 interactions by local gene therapy results in enhancement of antitumor effect of secondary lymphoid tissue chemokine. J Immunol. 2004;173:4919-28.

29. Onlamoon N, Rogers K, Mayne AE, Pattanapanyasat K, Mori K, Mori K, et al. Soluble PD-1 rescues the proliferative response of simian immunodeficiency virus-specific CD4 and CD8 T cells during chronic infection. Immunology. 2008;124:277-93.

30. Dai S, Jia R, Zhang X, Fang Q, Huang L. The PD-1/PD-Ls pathway and autoimmune diseases. Cell Immunol. 2014;290:72-9.

31. Wu H, Miao M, Zhang G, Hu Y, Ming Z, Zhang X. Soluble PD-1 is associated with aberrant regulation of $\mathrm{T}$ cells activation in aplastic anemia. Immunol Invest. 2009;38:408-21.

32. Wan B, Nie H, Liu A, Feng G, He D, Xu R, et al. Aberrant regulation of synovial T cell activation by soluble costimulatory molecules in rheumatoid arthritis. J Immunol. 2006;177:8844-50.
33. Greisen SR, Rasmussen TK, Stengaard-Pedersen K, Hetland ML, Hørslev-Petersen K Hvid $\mathrm{M}$, et al. Increased soluble programmed death-1 (sPD-1) is associated with disease activity and radiographic progression in early rheumatoid arthritis. Scand J Rheumatol. 2014;43:101-8.

34. Chen Y, Hu Z, Wang Q, Ge Y, Bai L, Wang X, et al. Generation and characterization of four novel monoclonal antibodies against human programmed death-1 molecule. Hybridoma (Larchmt). 2010;29:153-60.

35. Dulos J, Carven GJ, van Boxtel SJ, Evers S, Driessen-Engels LJ, Hobo W, et al. PD-1 blockade augments Th1 and Th17 and suppresses Th2 responses in peripheral blood from patients with prostate and advanced melanoma cancer. J Immunother. 2012;35:169-78.

\section{Submit your next manuscript to BioMed Central and take full advantage of:}

- Convenient online submission

- Thorough peer review

- No space constraints or color figure charges

- Immediate publication on acceptance

- Inclusion in PubMed, CAS, Scopus and Google Scholar

- Research which is freely available for redistribution

Submit your manuscript at www.biomedcentral.com/submit 